\title{
Some Considerations on the Continent/Content Theory in Psychoanalytic Technique
}

\author{
Julián Andrés Naranjo Orozco ${ }^{1,2,3 *}$ \\ ${ }^{1}$ Psychologist, Universidad Azteca, Mexico \\ ${ }^{2}$ Master in Psychoanalytic Clinic, Centro Universitario Emmanuel Kant, Mexico \\ ${ }^{3}$ Doctoral Student in Research in Psychoanalysis, Centro Universitario Emmanuel Kant, Mexico
}

*Corresponding author: Julián Andrés Naranjo Orozco, Psychologist, Universidad Azteca; Master in psychoanalytic clinic, Centro Universitario Emmanuel Kant; Doctoral student in research in psychoanalysis, Centro Universitario Emmanuel Kant, Mexico

\begin{abstract}
Objectives: 1) To introduce the continent/content theory of Bion, an author considered classic in psychoanalysis, but who is usually little understood; 2) To present my research on the field of application of the continent/content theory beyond that conceived by Wilfred Bion himself.

Method: The methodological strategy to achieve these objectives is the comparison/contrast between the instruments of this work: 1) Extracts of practical or concrete cases of subjects and patients; 2) Topics, subtopics, and/or problems proposed by Bion and other authors of psychoanalysis. This comparison/contrast will give us results on the applicability or not of the continent/content theory to the themes and problems of the cited authors and to the populations that are represented by each contemplation of an extract of practical or concrete case.

Population and sample: Each population considered in this article has been treated through numerous samples of particular cases and by different analysts. However, for the purpose of exposing the application of the continent/content theory in the different populations, a single case extract is taken as a sample per population. The populations considered here are: neurotics, users of crisis intervention services, borderline patients, and severely psychotic patients.

Procedure: In accordance with the objectives of this article: 1) I give a general introduction to the work of Bion; 2) I present the continent/content theory accompanying it with concrete examples, 3) I approach each of the populations with respect to the issue of applicability of the continent/content theory with the method already indicated and then clarifying the results corresponding to each population; 4) I present conclusions about the general applicability of the continent/ content theory in the populations considered.
\end{abstract}

Results: The treatment of psychotics and borderline requires a lot of application of continent/content, neurotics do not require so much but it is advisable to interpret their desire about that their anxieties to be returned in a processed way.

Crisis intervention service users also do not need a lot of continent/content application, but it is advisable to interpret their wish about that their ability of thinking returns.

In the treatment of borderline patients, it is counterproductive to interpret a wish about that their distress be returned in a processed way.

Severe psychotic patients usually require that container/ content be applied, initially, in a very elementary way: The analyst must only be present until he or she notices some favorable gesture from the patient.

Conclusions: The generalized applications of the continent/content in all analytical processes can be called formal interpretations, in contrast to the classical interventions, and so very valuable, that they would be called content interpretations.

\section{Keywords}

Continent/Content theory, Counter transference, Intervention in crisis, Psychosis, Borderline

\section{Introduction}

Wilfred Ruprecht Bion (1897-1979) born in Muttra, India, was a British physician, psychiatrist and psychoanalyst, of Huguenot descent and of Greek roots [1]. $\mathrm{He}$ is one of the psychoanalysts that I most admire for the depth of his reflections on the genesis of thought, 
psychoanalytic practice with a single patient and with groups. Bion's contributions to psychoanalysis are numerous: The love - hate - knowledge matrix, his postulate "without memory or desire", his conception of the unknowable, his notion of vertex, the continent/content theory, his discoveries about the Alpha function, on Beta elements, on group mentality, etc. As his discovery about the continent/content is addressed in this article, many of his contributions mentioned will be conceptualized in passing. Overall, Wilfred Bion's work is an excellent contribution to understanding the psychotic part of personality, thinking, and emotional experience.

\section{The Continent $(+) /$ Content $(\delta)$ Theory}

Bion conceives that we are born with a primary psychic apparatus and, of course, with sensitivity, with physical and psychological needs (like that of an external object to discharge our anxieties). From the beginning, the emotional bond between mother and child is strong; or being more precise, the breast-mouth bond. We are also born with a preconception of the chest, a something that bonds to the hunger that is felt with what is capable of satisfying it. When the mother responds to this preconception of the newborn, when she feeds him with her breast, the conception of the breast will be constituted, a conception that will continue to evolve [1].

At the beginning, the roles of continent (mother)/ content (child) - continent (child)/content (mother) are alternated. From the first experiences, continent/ content will gradually be interjected into the child. But this process can occur in two distinguishable ways from another fundamental concept in Bion's work: The lovehate-knowledge matrix.

First way: The mother has the ability to dream (reverie), the mother can respond to her baby by dreaming him; the mother is thus receptive, capturing the anguish that her baby through projective identification deposits in her (continent). The dreaming mother understands her baby and gives back to her son those anguishes and fears that the baby had projected on her, in a digested way, using the mother her secondary process. The baby calms down, he is not so hostile. The mother covers the physical and psychological needs of the newborn.

Let's consider for a moment how a sleepy baby might experience. It could be that he becomes distressed and feels drowsy as if he was losing his breath. A mother who dreams of her baby knows of this anguish and feeds him with a rhythm that accompanies with pleasure this loss of body tension as a willingness to sleep (She cradles the baby). The mother, using her secondary process, returns to the child that loss experienced is like each time entering a delicious state of floating body and without complaints. The baby more and more is depositing sensations in his mother and receiving sensations from her with more tranquility, with less hostility.
On occasions of need and its satisfaction and that satisfaction is not present, thanks to the dreaming mother and the not so hostile baby, the frustration of the satisfaction not present is modified, satisfaction not entered by the mother becomes a thought (content) which is thought by the baby, in his mind, thought (apparatus of thought - continent). Here we have the Alpha function that creates Alpha elements, that is, a thinking function that creates thoughts that are perceived as phenomena other than things themselves. The phenomena such as thoughts, the various sensations, created by the Alpha function from the impressions of the senses of the self, from the emotional experience, are the material of conscious thought and dream thought. In the integration of the interaction between the paranoid-schizoid position and the depressive position is the elaboration of the symbolic capacity.

This first path of the matrix corresponds to knowledge $(+C)$. It is rather here where we have the conception of the breast (of the provider and satisfactory), the thought, because, as we will see, this is not possible in the second way of the matrix. Thought makes frustration bearable. The conceptions and thoughts are an internal screen, they are a secondary process, they are an internal screen acquired by identification with the maternal capacity. The secondary process is a judgment of reality, a delay in the discharge of impulses [2].

Second way: The mother does not dream, rather she is very anguished and is not receptive, does not capture the anxieties and fears that her baby through projective identification would deposit in her. This mother is a barrier mother, she returns the anxieties and fears to her baby, those anxieties and fears that the baby project in vain, as it is, returned without prosecution. The neonate thus falls into the state of "nameless terror", in the paralysis of mental functioning. The non-satisfaction of the neonate's needs, deprivation, gives rise to primary envy towards the breast. The physical satisfactions of the baby do not coincide with the psychological satisfactions that he would require.

Let's go back to the case of the neonate who experiences anguish by being sleepy, but now assuming that the mother instead of dreaming about her child is a mother who is distressed by her baby. In this case, the baby deposits in his mother, of course, his anguish of loss of breath and the mother, when she is anxious, returns to her baby that same anguish of losing breath, vitality. This constitutes a terror for the baby that has no name for him.

Here the newborn is very hostile and aggressive. In those situations of need of the chest, in which the same is not present, there is no tolerance to frustration. The chest not in the inside is bad chest, something that persecutes and the baby flees. The contents are internal objects that must be undone and the psychic apparatus 
(continent) is an apparatus for the expulsion of internal objects. There is no Alpha function or Alpha elements, what there is less knowledge $(-C)$, Beta elements (things in themselves), not phenomena. Here, where the internal screen does not exist, in any tension situation, the anxiogenic aspect is ejected projectively into an external object. Here what is there is attack - flight with respect to thought and bond. There is also avid persecution for the lost object, dependence increased by material comforts; an inability to experience love for oneself or for others, a total dependence on the inanimate object that only him (the subject) can provide the means of subsistence [2].

Let us accompany what was expressed in the previous paragraph with our case of the baby who is distressed by being sleepy and with a mother who is distressed. In the course of situations in which he deposits his anguish on his mother and it is returned to him by his mother without prosecution, the baby will not tolerate this frustration of non-satisfaction (of non-breast) and those things that comes to him from his emotional experience will not appropriate them, but will expel them out of himself, he will assign them in a bizarre way to an external object while his very non-tolerance to frustration leads him to the external object to provide him satisfaction. However, any external object is like that mother who returns the anguish without processing and thus the objects, the things themselves, are what is longed for and, at the same time, what pursues him, what haunts him. This is the origin of psychotic distress and hallucination.

The psychotic makes projective identifications of parts of his mental apparatus and of intense emotions within the physical world that surrounds him (physical world - objects - bizarre objects). That baby who is distressed by being sleepy, and whose mother is distressed, will become hostile in human relationships, more and more, and as he grows, it will be noticeable that he is greedy for material objects that provide comfort, assigning to them magical power, but at the same time it will give people and objects a diabolical and persecutory power, powers that are projective identifications of their mental apparatus and intense emotions. If he projects his vision function, he will experience that the sofa sees him, watches over him and controls him.

The continent/content theory is of explanatory, diagnostic and intervention value. In an analytic process, this same patient may experience that his analyst is incompetent and that both he and his analyst are being controlled by the sofa. Thus, the analyst, after a rigorous exploration via transference psychosis and after the anguish of chaos by the gaze and vigilance of sofa that, in reality, comes from the patient himself, could contain and return that anguish to the patient but in a metabolized way: "You are distressed by the chaos of having been observing your nurse's legs when she was sitting on the sofa, there her skirt was higher than normal, you made your nurse wait on the sofa to continue observing her secretly". After this intervention, the patient may stop experiencing that the sofa is watching and controlling him and regain his credibility in the ability of his analyst.

In analytical processes with psychotics, the continent/content is a main tool that is used many times on the same patient, because when treating psychosis we must focus mainly on forming an apparatus to think that belongs to the patient.

\section{Continent/content theory and the analytic pro- cess in neurotic patients}

The same continent/content theory that exposes the origin and functioning of psychosis was, of course, applied by Bion in the analytical treatments of psychotic patients or those with strong psychotic features. Would the continent/content theory have a much broader applicability than Bion managed to give it? Bion himself postulated that we all have a psychotic part of the personality [3] and this leads to exploring the scope of the continent/content theory, in all of us, with the methodological strategy that I also used to better explain Bion's theory: To Compare practical or concrete cases with areas or problems that different authors of psychoanalysis propose.

I want to start with a comparison between a clinical case and the setting and holding in the psychoanalytic process of neurotics. It was a comparison already made by a well-known author in psychoanalysis: Ricardo Horacio Etchegoyen.

Etchegoyen, Argentine psychoanalyst and president of the IPA in the past, sustains that, also for neurotics, the continent function of analysis and analyst means that the patient's anguish and fears can be received and then returned to the patient in a digested way. This makes the setting and/or holding (support for the patient) acquire a more abstract and transcendent dimension. The holding is no longer left with the sole factual function of holding in the arms, but now has this invaluable and, at the same time, abstract function of continent for the patient [4].

The continent function is pertinent to separation anxieties, those that belong precisely to that order of separation from the maternal breast, from the breastnot inside (the mouth). Etchegoyen offers us an example of what has been said so far, but I prefer to cite a case of mine similar to his. The reason is that Etchegoyen asks himself about the continent/content: How far is it received and since when does it begin to be returned (by analyst) according to the counter transference? It is to answer this question that I cite a case of my own.

Mr. D, a middle-aged man, had been in treatment for three weeks with me and a transfer was already 
in place. Our sessions were twice a week, but, due to Mr. D's occupation, the sessions were on Tuesdays and Wednesdays, with a six-day waiting period between Wednesday's session and next Tuesday's. The two days we had sessions were relatively calm for Mr. D, even more calm than before the start of treatment. On those two days, Mr. D attended to his work and family affairs with few apprehensive thoughts about failure to carry out his affairs. But in the last week and in the six days that elapsed between Wednesday's session and the following Tuesday, Mr. D fought with everyone and retired to watch the soccer game channel for hours and hours while a great lots of apprehensive thoughts about being able to fail in your everyday affairs. When the session on Tuesday arrived, Mr. D communicated to me the apprehensive ideas he had and expressed the anguish that still accompanied them. Only once I answered him about his anguish by punctuating the aspect of the doubt that assailed him, without falling into repetition and then I interpreted that he wanted me to be a support for him by returning what he deposited in me in a processed way.

In the session of next day (Wednesday) the patient communicated to me a dream that he had the same night as yesterday, Tuesday: He was about to take his daily bath and his bathtub humidifier was not working. Interestingly, the humidifier provider called him at that time to ask about his satisfaction with the product and so Mr. D took the opportunity to tell him that the humidifier was not working. The provider, who in Mr. D's dream had my tone of voice, reassured Mr. D by telling Mr. D that when he had any problem with the humidifier he could call him and that was solved provided that Mr. D should not put the humidifier on high power because the seasonal period did not warrant doing so.

Mr. D enthusiastically recounted the dream to me and no further clarification was necessary about the dream. I was the provider who was there to give him support about his bathroom purifying device and the support I provided was aimed at greater autonomy so that Mr. D could handle his humidifier more and more by himself. After these events, the accompanying anguish of what Mr. D communicated to me was less and less intense and the interpretations that I could give him could be more complex in content.

Results: While with a psychotic patient it is not necessary to interpret that he wants one to be his support by returning his processed anguish because mainly his thought apparatus should be formed in him, in the case of the neurotic patient it is necessary to interpret that he wants you to be his support because in neurosis, mainly, it would be necessary to restore the patient's ability to think instead of emphasizing the formation of a thinking apparatus.

Regarding the question that Etchegoyen asks himself: How far is it received and since when does it begin to be returned (by analyst) according to the counter transference? I answer that the measure to receive and to return in the continent/content can be estimated when we can scrutinize in the counter transference in which we could fall into counter-projective identification and thus we do not fall into it. Let us remember that counter-projective identification refers to the analyst acting on the projective identification of the patient. In the case of my patient I mustsay: Mr. D is an obsessive neurotic and makes projective identification of reiteration. I managed to scrutinize that if I repeatedly highlighted the aspect of doubt in his apprehensive ideas, then it would be like acting his projective identification, so this gave me the measure to receive and return, of all the occasions that he deposited his ideas and apprehensive anguish my return should be only one.

\section{The continent/content theory and users of crisis intervention services}

Intervention in crisis situations by telephone is a form of psychological support that can be provided with psychoanalytic guidance. In my practice as a volunteer at Saptel, a Mexican institution for psychological care and support by telephone, I did an intervention to a patient who was going through a crisis situation using continent/content. The reason is simple: A very pronounced crisis or internal conflict situation destabilizes the ability to think [5]. Therefore, when this user of the service in a desperate and anguished way deposited a lot of problems with me, I interpreted it precisely that he wanted me to give him back his ability to think and that it was lawful for him to continue downloading everything he brought to deposit it in me. This greatly facilitated the emotional discharge and the user in a few moments reached a feeling of relief. After this, I mentioned that same event that he was wanting about that his ability to think was returned involved that precisely referred his ability to think and, immediately, I made a few practical suggestions that began by saying "it could be thought ..." The user very soon began to follow the ways in which the events to be resolved could be thought.

\section{Continent/content theory and borderline patients}

Wilfred Bion used continent/content also with patients who had pronounced psychotic features. This makes us consider borderline patients. Without ignoring that borderline refers to its own and distinguishable organization, which is not something that is between neurosis and psychosis as it used to be conceived some years ago, the question of whether the interpretation should be made with a borderline patient, as well as with the neurotic, that he wants his analyst to be his support so that he returns his processed anguishes, or if, on the contrary, one should use continent/content with abstention from such an interpretation, as is done with the psychotic, is one question that is unavoidable since it is obvious that such an interpretation is made 
or not made. A colleague who, even though he was not very clear about whether his patient was borderline or not, interpreted his "wish" for him, as his analyst, to be his support for processed returns and the result was the patient's flight from treatment.

It has been discovered that borderlines are at a crossroads in terms of their relationships: They depend on the other as a support to their self, but, at the same time, they fear merging with the other [6]. If a borderline patient is misinterpreted that he wants his analyst to be a support for processed returns, the results can, of course, be flight from treatment.

\section{Continent/content theory and severely psychotic patients}

Psychotic patients vary, of course, in their levels of severity. With the most severe psychotic patients or with a very acute psychotic outbreak, it is advisable to keep in mind Margaret Mahler's theoretical proposal on different degrees individuation/separation with respect to the other [7]. The more precarious individuation/ separation of one patient with respect to the other, the more fused patient is with the other, the more serious her condition will be. How does this affect clinical practice? In the recommendation that, when the patient is very serious or in the face of a very acute psychotic outbreak, the analyst should only be present at the beginning until he or she notices a favorable reaction, a gesture, on the part of the patient, cause the presence of the analyst. Another colleague, who was in charge of interviewing a psychotic patient in acute outbreak at an institution, put Mahler's recommendation into practice and this was, of course, a proper continent/content application, from a very elementary level. This colleague, with patience, was able to carry out the interview where many others had failed.
It is worth clarifying that any intervention for psychotic patients or those with a pronounced psychotic personality side must be interdisciplinary.

\section{Conclusions}

It can be clearly seen that the continent/content theory is always applicable in the analytical process with all types of patients. It is for this reason that I propose that the applications of continent/content be called formal interpretations, that is, interpretations that, based on the analyst's dreaming capacity, are aimed at interpreting the state, the form, in which the patient, in contrast to the also very valuable interpretations of content that usually allude to the Oedipus complex, the primal scene, castration, etc.

The application of the continent/content theory in any analytical process is due to the fact that we all have a psychotic side of the personality, for the application of formal interpretations it will always be necessary to keep in mind to scrutinize the countertransference in relation to the counter - identification projective.

\section{References}

1. Schmid-Kitsikis E (2001) Wilfred R Bion: Life and Psychoanalytic Thought. Madrid: Editorial Biblioteca Nueva, SL.

2. Bion W (1987) Learning from experience. Mexico: Paidós.

3. Bion W (1977) Thinking again. Buenos Aires: Horme.

4. Etchegoyen $R$ (2002) The foundations of psychoanalytic technique. Buenos Aires: Amorrortu editores.

5. Gaitán A (2002) Saptel, Procedures Manual. Latin American and Caribbean Regional Council of Mental Health, AC.

6. Lerner $H$ (2007) The convulsed psychoanalytic clinic. In: Border Organizations, Ed. Lugar, Lerner H, Sternbach S. Frontiers of Psychoanalysis, Buenos Aires.

7. Mahler M (1984) Studies 1: Childhood psychosis and other works. Buenos Aires: Paidós. 